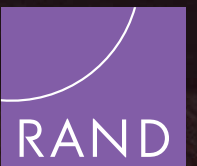

EUROPE

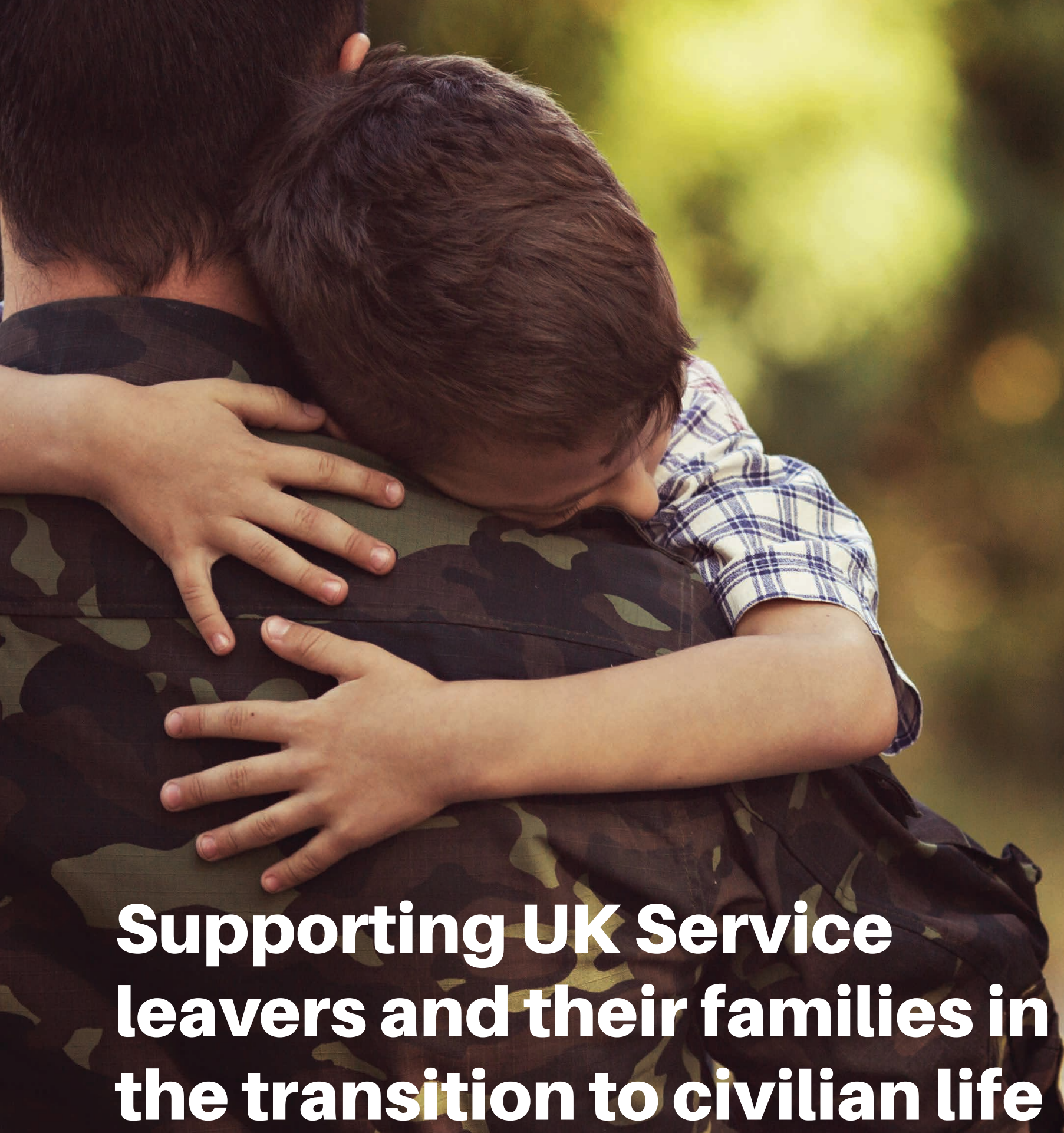

Each year approximately $\mathbf{1 7 , 0 0 0}$ personnel leave the UK Armed Forces and return to civilian life. There are challenges faced by the families of UK service personnel adjusting to civilian life. The families are diverse, although $\mathbf{4 7}$ per cent of the UK Armed Forces are married or in a registered partnership. However, there remains limited evidence available about the challenges faced by the families of UK Service personnel adjusting to civilian life.
It is recognised that families play an important role in achieving a successful transition to civilian life. However, research to date has predominantly focused on support provided to families when their family member is still serving, is deployed on active duty, or has returned from active duty. Little research appears to be focused on the issues associated with this transition, or indeed the role of the family in achieving a successful transition into civilian life. 


\section{The research}

RAND Europe was commissioned by the Forces in Mind Trust (FiMT), a charity which aims to improve the lives of ex-Service personnel and their families, to conduct the first ever systematic review of literature on the support provided to families in transition from military to civilian life in the UK.
The purpose of the review was to develop a better understanding of the available evidence base and potential gaps in the literature on families in transition. This involved a systematic search of relevant databases and an objective interrogation of academic and grey literature.

RAND Europe's review focused on four research themes highlighted in a 2015 report from FiMT, which aimed to develop a better understanding of the support needs of the families of Service leavers. These four areas are:

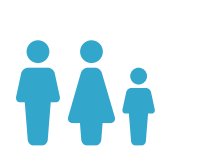

Engagement with families - Previous FiMT research highlighted a low utilisation by Service families of services provided by the UK Ministry of Defence (MOD) and voluntary organisations, many of which are designed to increase awareness of the different issues that families need to consider in the transition to civilian life.

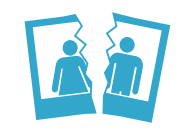

Family breakdown - The scale and nature of relationship breakdowns was another area flagged for further investigation, with anecdotal evidence that active service, long overseas postings and transition from military to civilian life can lead to the breakdown of families.

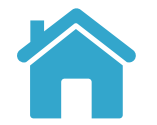

Housing support - Previous FiMT research highlighted that housing is the greatest financial issue facing many families moving back into civilian life, particularly if they have been in service accommodation.

Spousal employment - The FiMT reported on low employment rates were reported among spouses of Service leavers, in comparison with the wider civilian population. 


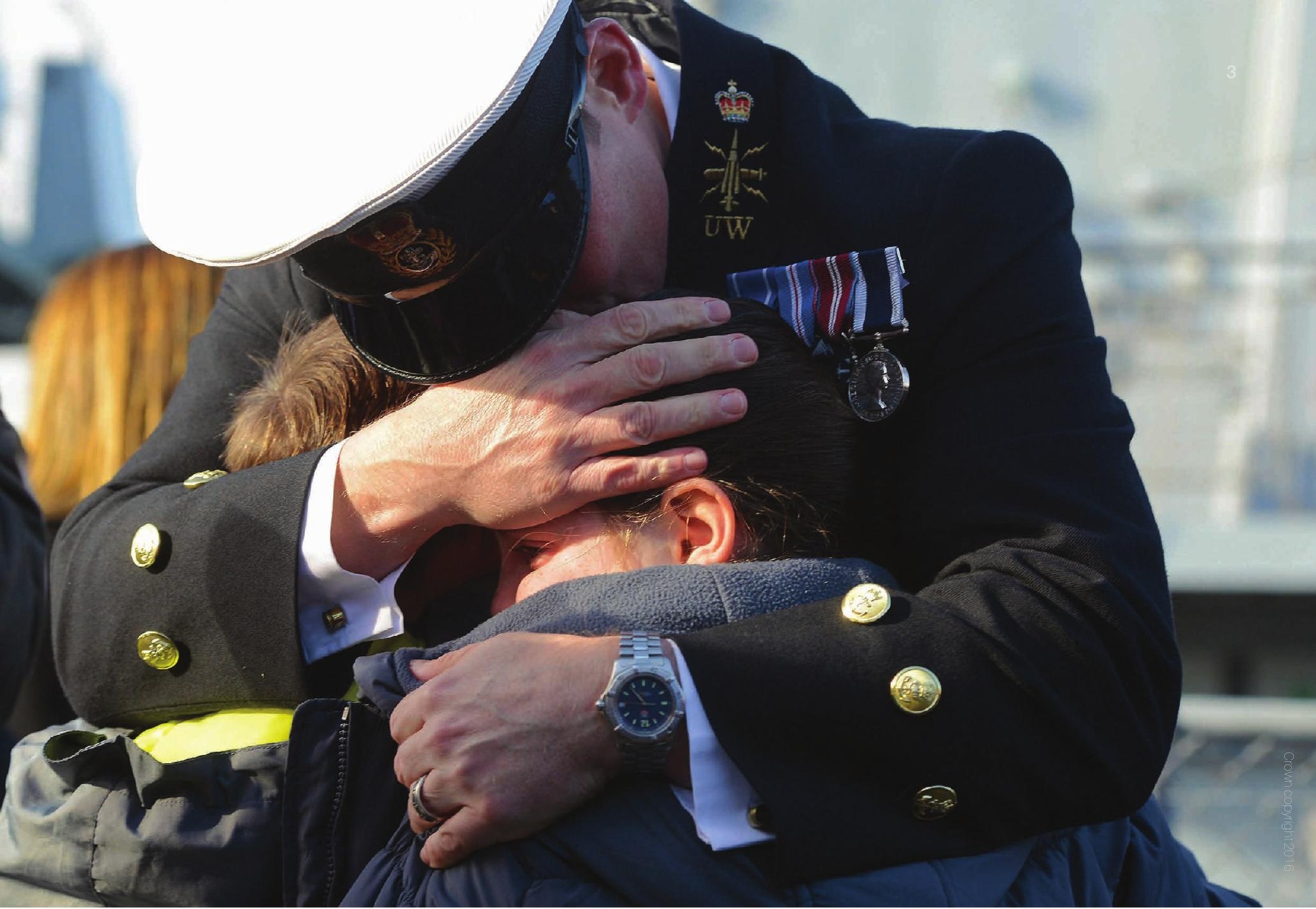

\section{The findings}

Evidence was found to be limited across all four research themes. Very little of the examined source material focused specifically on the issue of transition, with most sources addressing issues around deployments and Service life more broadly. The challenges facing the families of UK military personnel leaving Service life were inadequately reflected in the literature. They require further attention in order to better develop support services that meet the needs of Service leavers' families. Furthermore, the literature focused primarily on the US context, with the relevance and applicability of the findings to the UK being under-assessed.

The following evidence gaps were also identified in the review. There was:

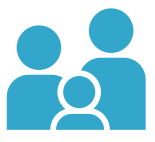

Very little research examining the impact of military Service - and indeed transition - on family stability.

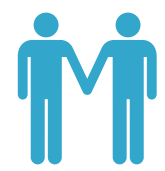

Very little research on 'non-

traditional families', such as same-sex partnerships, remarried personnel, and personnel living in stepfamilies and binuclear families, where two households are connected by a common biological child.
Very little UK-focused research on the impact of transition on spousal employment. In particular, the review found a shortage of spousal employment research focusing on the husbands or partners of female personnel, with the majority of research focusing on the wives of male personnel.

No literature aimed at understanding the needs of all types of Service leavers in the UK in relation to housing. 


\section{Recommended future research}

In order to better engage with families in transition and provide appropriate support across the four thematic areas, there is a need for a stronger evidence base that systematically investigates the issues faced by different types of Service leaver families. The following recommendations were developed for research funders and researchers, as well as for the MOD, public bodies and other relevant service providers.

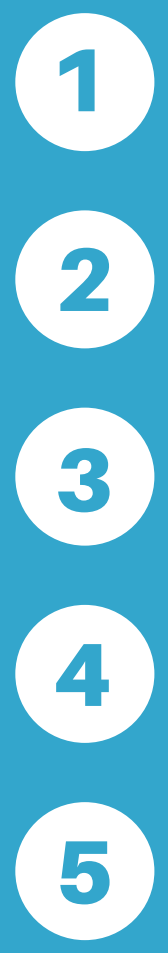

More comparative studies and funding for longitudinal research should be commissioned and allocated by research funders.

Evaluations of different schemes and programmes for UK Service leavers should be allocated more research funding. In particular, the MOD should evaluate and monitor its transition support for UK Service leavers and their families.

Funding for a 'mapping study' of existing support for UK Service leavers should be made available.

Funded studies should clearly differentiate between different types of Service leavers (e.g. retired, injured, early-Service leavers) and provide balanced insights covering different family structures.

An assessment should be conducted of the potential applicability of international research and programming to UK Service leaver families to inform the future development of policy and support programmes.

\section{Conclusions}

There is a lack of systematic and objective evidence of the challenges faced by UK Service personnel and their families when adjusting to civilian life. In particular, there is a shortage of rigorous research on engagement with families, family breakdown, housing and spousal employment. RAND Europe recommends that further in-depth research should be conducted within these four areas. This will be vital in informing future research directions, research funding prioritisation, and practical actions and policymaking in the area of Service family support.

This summary describes work done by RAND Europe documented in Families Support to Transition: A Systematic Review of the Evidence by Susanne Søndergaard, Kate Robertson, Erik Silfversten, Brent Anderson, Catherine Meads, Agnes Schaefer and Jody Larkin, RR-1511FiMT, 2016 (available at www.rand.org/t/rr1511). To view this summary online, visit www.rand.org/t/rb9928. RAND Europe is a not-for-profit organisation whose mission is to help improve policy and decisionmaking through research and analysis. RAND Europe's publications do not necessarily reflect the opinions of its research clients and sponsors. RAND ${ }^{\circledR}$ is a registered trademark.

The research described in this brief was funded by the Forces in Mind Trust, a Big Lottery Fund endowed spend-out Trust.

\section{FiMT \\ forces in mind trust
suucessful sustainabie transition

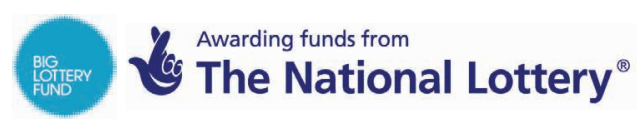

Limited Print and Electronic Distribution Rights: This document and trademark(s) contained herein are protected by law. This representation of RAND intellectual property is provided for noncommercial use only. Unauthorised posting of this publication online is prohibited. Permission is given to duplicate this document for personal use only, as long as it is unaltered and complete. Permission is required from RAND to reproduce, or reuse in another form, any of its research documents for commercial use. For information on reprint and linking permissions, please visit www.rand.org/pubs/permissions.html. 